\title{
Grupo de Família: Relato de Experiência Acerca do Trabalho com Cuidadores de um Hospital Psiquiátrico na Cidade de Crato - CE
}

\author{
Anna Karinne Melo Barreto $^{1}$; Leda Mendes Pinheiro ${ }^{2}$
}

\begin{abstract}
Resumo: O presente artigo traz um relato de experiência a partir da vivência da autora enquanto facilitadora de um grupo de família que cuidam de internos de um hospital psiquiátrico da cidade de Crato - CE. Os encontros aconteceram por um período de seis meses, com uma reunião semanal, durando uma hora cada encontro. Foi utilizado para descrição desse trabalho o método heurístico que deixou a pesquisadora livre para expor seus sentimentos e percepções diante do movimento desse grupo. O objetivo principal desse trabalho é mostrar a importância e os benefícios de um grupo terapêutico para cuidadores de pessoas que possuem problemas mentais e como esse processo é percebido pela autora enquanto observadora participante e facilitadora. Diante desse cenário, fica perceptível a importância do trabalho com grupos e os benefícios encontrados para cada participante através do compartilhamento das experiências, do acolhimento mútuo e do suporte terapêutico.
\end{abstract}

Palavras - chave: Relato de experiência. Grupo de família. Hospital psiquiátrico.

\section{Family Group: Report of Work Experience About Caregivers of a Psychiatric Hospital in the City of Crato - CE}

\begin{abstract}
This article presents a report from the experience of the author as facilitator of a group of family caregivers of inmates in a psychiatric hospital in the city of Crato-CE. The encounters happened for a period of six months, with a weekly meeting lasting an hour each gathering. For description of this work, the heuristic method was used, which allowed to the researcher freedom to expose her feelings and perceptions in front the movement of this group. The main objective of this paper is to show the importance and benefits of a therapeutic group for carers of people who have mental problems and how this process is perceived by the author as a participant observer and facilitator. Given this scenario, it is noticeable the importance of working with groups and the benefits found for each participant through the sharing of experiences, mutual care and therapeutic support.
\end{abstract}

Keywords: Experience report. Family group. Psychiatric hospital.

\section{Introdução}

Este artigo trata de um relato de experiência da autora enquanto facilitadora de um grupo terapêutico de familiares de internos de um hospital psiquiátrico na cidade de Crato - CE. Durante o período de seis meses foram realizados encontros semanais com duração de uma hora. O objetivo dessa experiência é relatar os sentimentos e a percepção da autora como facilitadora desse processo, apresentando os aspectos relevantes do existir do grupo para as famílias cuidadoras de pessoas com transtorno mental, mostrando a importância e os benefícios do acolhimento e do suporte para com esses familiares. A experiência com o grupo de família foi de grande importância principalmente pela grande relevância social nessa área de trabalho pretendendo a autora explorar cada vez mais, e compreender melhor esses espaços de grupo. 
Foi utilizado como metodologia da pesquisa, o método heurístico que servirá de suporte para que a autora possa relatar a sua experiência diante do grupo pesquisado. Esta se expressará livremente, a partir do funcionamento do grupo se valendo das falas, das experiências e do movimento do grupo.

Considerando os fatores positivos existentes dentro de um setting grupal e em especial ao grupo em questão, percebe-se a grande importância da existência dos grupos terapêuticos por dizer respeito a uma ferramenta do cuidado muito utilizada nos dispositivos de saúde mental, bem como por seu público - alvo ser composto por familiares e cuidadores de pessoas que vivenciaram internações psiquiátricas. O presente trabalho ressalta a percepção da autora acerca do acolhimento a esses cuidadores e familiares.

A partir desse estudo a autora está respaldada e atualizada para mostrar a importância de se manter um grupo de família que cuidam de pessoas com transtorno mental, ajudando assim, as pessoas que necessitam de atenção e de acolhimento em busca de uma melhor qualidade de vida para todos envolvidos nesse contexto.

É notória a importância do esclarecimento da população acerca dos aspectos que englobam a relação cuidador e paciente, já que esta vai além dos muros de um hospital psiquiátrico ou dos dispositivos de saúde disponíveis, pois serviria como outro apoio aos familiares e facilitaria a reinserção da família como um todo, diminuindo as dificuldades e os preconceitos existentes nesse convívio social, visto que a sociedade não sabe se portar diante de situações que fujam de uma realidade e comportamentos ditos normais. Dessa forma, seria interessante esclarecer as medidas de intervenção, a importância do apoio e da compreensão da população para que essas pessoas possam ter uma vida integrada com a sociedade com menos sofrimento.

Portanto, diante de toda essa experiência ficam claros os aspectos que causam sofrimento, desamparo e incompreensão, mostrando a importância do acolhimento, do suporte e apoio tanto das políticas públicas quanto da sociedade como um todo, trazendo a partir dos sentimentos e percepções da autora, a experiência de quem vive nesse contexto de cuidado para com um familiar que tenha algum tipo de problema mental.

\section{Referencial Teórico}

\section{Hospital Psiquiátrico e Família}

No século XVIII, Phillippe Pinel passa a perceber a loucura como doença, intervindo no tratamento dos psicóticos, tornando o lugar do asilamento como área médica, da psiquiatria. Nesse mesmo período começou a fazer parte do tratamento, o isolamento social onde o doente era afastado da sociedade, inclusive da família com a justificativa de proteger essas pessoas contra a falta de 
disciplina e a desordem moral considerando isso características da loucura. Além disso, a família também era responsabilizada pelo adoecimento dessas pessoas, o que contribuía para que os afastassem de seus familiares. O Estado passou a se responsabilizar pelos cuidados da pessoa com transtornos mentais autorizando um contato mínimo entre a família e seus entes adoecidos. Dessa forma o vínculo nessa relação ia se desfazendo, pois a internação passou a alongar-se muito e o doente ficava cada vez mais isolado (MELLO, 2005).

Em 1804 no Rio de Janeiro foi criado o primeiro hospício que recebeu o nome de Hospício D. Pedro II, nele as pessoas com transtorno mental ficavam isoladas. O intuito desse isolamento seria separar o doente da família e da sociedade, pois estas eram responsabilizadas em parte pela formação da doença mental (AMARANTE, 2010). Assim, o modelo hospitalocêntrico e o formato do asilamento ganham espaço rapidamente no Brasil.

Quando este hospício foi inaugurado, dos seus 350 leitos, apenas 144 estavam ocupados e após um ano de funcionamento estava com lotação esgotada. A partir de 1904, nota-se um excesso de doentes, levando a uma superpopulação (BRASIL, 1998, p.12).

Em 1970, a responsabilidade de cuidar de pessoas com transtorno mental retorna para a família, onde a mesma no decorrer do tempo assume várias funções para manter o cuidado para com o seu familiar, deixando-a sobrecarregada (MELLO, 2005). No final dessa década, inicia-se no Brasil a reforma psiquiátrica trazendo um novo olhar para esse modelo hospitalocêntrico (AMARANTE, 2010).

Para Macedo et al. (2009), com a reforma psiquiátrica o doente mental passa a ser internado apenas nos momentos de crise aguda e são oferecidos tratamentos alternativos para os doentes que estejam em melhor estado, assim como, não ser afastado da família e procurar facilidades e incentivos para sua reinserção social. Segundo Gonçalves e Sena (2001), a desinstitucionalização torna-se o objetivo principal da Reforma psiquiátrica no Brasil visando o aniquilamento do manicômio e as normas que seguem esse modelo. Além dos profissionais de saúde mental, a própria sociedade discute a substituição desse modelo por outras práticas terapêuticas, incluindo os cuidados à família.

Para a família é muito difícil quando um de seus membros adoece mentalmente ter que enfrentar a quebra e os conflitos que surgem na sua estrutura, o que torna o convívio bastante desgastado e atribulado. Além disso, a família também não consegue lidar com a vergonha de se ter um familiar com algum tipo de transtorno mental, pois segundo Melman (2001, p. 23) "A doença mental continua sendo com frequência, o motivo de muita vergonha para os familiares". A família acaba por não aceitar a condição do seu ente e o mantém isolado da sociedade. Melman (2001, p. 37) reitera: "Para algumas pessoas, apresentar um irmão ou um filho doente é um fato absolutamente intolerável, inaceitável." Isso dificulta ainda mais a reinserção do paciente no meio social, ainda mais 
que a vida em comunidade é o que fortalece um grupo e quando isso é perdido ou modificado, gera uma sensação de impotência e negação.

A família tem que lidar também com a culpa que sente e que lhe é dada pela sociedade. Melman (2001, p. 38) fala: “já que a família é tudo, também é responsável por tudo. Se tudo se remete a família, tudo é culpa da família." Isso afeta intensamente o início do tratamento do familiar adoecido, aumentando dessa forma a relutância em procurar o que corresponde ao melhor tratamento para pessoas com essa patologia, assim a família mais uma vez carrega o peso e a responsabilidade desse cuidado (MELMAN, 2001).

Para Campos e Soares (2005), quando se estuda a relação familiar e a doença mental, pode-se notar o choque da representação da doença nesse meio, pois surge uma desordem a partir dos enfrentamentos da família quando os seus entes mudam o comportamento e a dificuldade de corresponder às responsabilidades que lhes são exigidas quando passa a assumir esse papel de cuidador. Essas responsabilidades tornam-se mais ampliadas também, pois o sistema de saúde não deixa claro sobre respostas definitivas sobre o que causou a doença e como será a evolução da mesma.

Conforme Goldman (1982 apud CAMPOS; SOARES, 2005), o peso que a família carrega é determinado pelo estresse emocional e econômico a que se sujeita quando seu familiar obtém alta de um hospital psiquiátrico e volta para casa, em especial quando os vínculos são desfeitos como nos casos de pacientes que têm sua doença considerada crônica e passaram bastante tempo internados em hospitais psiquiátricos.

A política de saúde mental tem o dever de oferecer auxílio aos familiares já que favorece a inserção da família de pessoas com transtornos mentais graves na assistência, portanto é necessário que os profissionais criem no dia a dia das instituições dispositivos terapêuticos que sirvam de suporte para contemplar as necessidades dos cuidadores (MELLO, 2005), como é o caso da Estratégia de Saúde da Família (ESF) que segundo Macedo et al. (2009), não pensa apenas no sujeito, mas também direciona o cuidado para a família, visando orientar, estimular, acolher e estabelecer ou fortalecer os vínculos, com o apoio da comunidade e dos profissionais de saúde. No Centro de Atenção Psicossocial (CAPS) encontra-se também esse apoio, pois segundo Grandi e Waidmar (2011), essa instituição abre as portas para além dos cuidados com o as pessoas que sofrem de transtorno mental, preocupando-se também em acolher e cuidar da família, já que o sujeito ao regressar da instituição psiquiátrica, passa mais tempo junto dos seus familiares.

Sendo assim, percebe-se a importância de um acolhimento direcionado à família, sendo os grupos terapêuticos uma opção possível, pois é neles que os membros compartilham as experiências, e encontram apoio a partir da troca das suas vivências. Dessa forma, os familiares sentem-se mais fortalecidos e capazes de enfrentar os problemas do dia a dia (MELMAN, 2001). Para Santim e Klafke (2011), o trabalho com as famílias vai além de olhar para elas como sendo apenas um familiar de um doente mental, e não ajudar somente no que se deve fazer ou não para a recuperação do ente adoecido, 
e sim estabelecer relações de cuidado com o cuidador preocupando-se no bem estar desse familiar, de como é cuidar de alguém nessas condições e ao mesmo tempo como ele se sente com esse papel. Corroborando com essa ideia Zimerman (2004), fala que o enquadre grupal proporciona a produção de um novo ambiente, onde os participantes experienciam emoções que não ficaram bem resolvidas seja na família ou com pessoas que convivam no dia a dia, com o intuito de reconstruir esses laços que foram interiorizados de forma adoecida.

\section{O Trabalho com Grupos}

A psicologia aplicada a grupos surge da convergência entre a psicologia, implicada das questões relacionadas ao psiquismo individual e da psicologia social, envolvida na interface entre a psicologia e a sociologia. Os primeiros trabalhos nessa área datam do início do século e consistem no início das práticas da psicologia aplicadas aos grupos (OSORIO, 2009).

Freud discute em obras como Totem e Tabu e o Mal Estar na Civilização questões relacionadas à formação e existência de um inconsciente grupal, não chegando a conceber um método para trabalhar com os coletivos, mas discutindo seus mecanismos de formação e representações. Esse autor utilizou-se dos trabalhos do sociólogo francês Gustav Le Bon e de sua análise das massas para conceber uma psicologia dos povos (FREUD, 1921).

Foram dois psicanalistas os pioneiros nos trabalhos com grupos, a saber Bion e Pratt, em experiências com o exercito inglês e num dispensário de tuberculosos pois foi percebido que ao dividirem seus problemas, houve um crescimento na autoestima desses pacientes o que contribuiu para o progresso dos mesmos. Esse método expandiu-se para saúde mental e depois para outras doenças. Numa situação social emergencial, a psicologia aplicada a grupos surge como a possibilidade para lidar com grandes contingentes em situação de urgência (OSORIO, 2009). A partir daí as perspectivas teóricas se ampliam, fomentando práticas que estenderam os trabalhos em grupos.

Em seguida, teóricos como Kurt Lewin e seu trabalho sobre lideranças, Pichon Rivière concebeu a teoria do vínculo e dos grupos centrados na tarefa, ou grupos operativos, e Moreno criador do psicodrama, passaram a conceber métodos de trabalho e técnicas, aprimorando os conceitos e formas de trabalhar com grupos. Dessa forma, a psicologia aplicada a grupos e a psicoterapia grupal emerge como forma, teoria e método (OSORIO, 2009).

Os grupos podem ser fechados e abertos, heterogêneos e homogêneos. O grupo aberto, é o tipo trabalhado no CAPS e nos hospitais psiquiátricos, está sempre disponível a receber novos participantes o que traz uma maior vantagem sobre o grupo fechado nesse aspecto, pois é como se estivesse sempre começando, o que faz com que as pessoas passem a se apresentarem e se conhecerem a cada encontro. Já o grupo fechado permanece sempre com o perfil delimitado do início da formação do grupo, mas dessa forma possui uma vantagem sobre o aberto que é conseguir mais rapidamente criar e fortalecer o 
vínculo, e assim propiciar um espaço de confiança e afetividade fazendo com que se atinja mais rápido a maturidade, que é um fator necessário para alcançar seus objetivos. Os grupos homogêneos são aqueles que têm características semelhantes e se tornam mais coesos. De maneira oposta, os heterogêneos são os que sofrem variações dessas características tais como idade, saberes, ou classe econômica e social (GUIMARÃES et al., 2008).

Yalom e Molyn (2006), descobriram que existem fatores terapêuticos específicos usados pela psicoterapia de grupo, e buscaram saber quais eram para que pudessem entendê-los a partir de vários tipos distintos de grupos terapêuticos quais trajetórias comuns ajudariam seus componentes a mudar. São onze fatores terapêuticos presentes, em maior ou menor grau, nas psicoterapias de grupo: instilação de esperança; universalidade; oferecimento de informações, altruísmo, desenvolvimento de técnicas de socialização, comportamento imitativo, catarse, reedição corretiva do grupo familiar primário, fatores existenciais, coesão do grupo, aprendizagem interpessoal.

Para os autores, as técnicas e intervenções realizadas pelo terapeuta, incluindo o próprio grupo são ferramentas que proporcionam mudanças. A relação membro-membro é um grande passo para o crescimento e para as mudanças, pois percebem que não estão sozinhos nesse contexto de sofrimentos e compartilham experiências semelhantes aprendendo a encarar os problemas com outro olhar.

Corroborando com essa mesma ideia, Guimarães e Contel (2009), falam que na psicoterapia de grupo é importante que haja uma boa interação entre o grupo, pois dessa forma seja qual for a modalidade, a força terapêutica e o poder para a mudança derivam dessa interação, onde o próprio grupo gera o fator terapêutico, contribuindo para o progresso de cada um.

Nos Estados Unidos, em 1920, surgem trabalhos em grupo direcionados para pessoas que sofrem de transtorno mental, e a grupoterapia tem sido uma importante aliada para a promoção e recuperação da saúde mental, onde tem sido bastante usada nos serviços ambulatoriais. No Brasil, a reforma psiquiátrica se utiliza dos dispositivos grupais desde o seu início (GUIMARÃES et al., 2008). Para Yalom e Molyn (2006), a psicoterapia de grupo é uma forma extraordinária de psicoterapia, considerando o setting de grupo como sendo uma ferramenta muito poderosa, podendo ser utilizada no contexto da saúde mental desde a prática com as pessoas adoecidas até seus familiares, como ferramenta de suporte e acolhimento.

Nos tocantes aos trabalhos de grupo com famílias, algumas experiências ao longo da história podem ser tomadas como exemplo como a do Hospital de Nova York em 1950, que concebeu o tratamento de familiares a partir de uma terapia em grupo com Peter Laqueur, onde foi trabalhado a princípio com familiares de pacientes com esquizofrenia, porém depois se estendeu para outras patologias em variados modelos de serviços em saúde mental. A terapia de grupo tinha por objetivo fazer com que os membros aprendessem uns com os outros, a partir do compartilhamento de suas experiências, buscando uma evolução na comunicação e um melhor entendimento das circunstâncias 
vividas, dessa forma os participantes exerciam a posição de coterapeutas, onde se ajudariam a buscarem várias possibilidades para a mudança e encarar as dificuldades (PONCIANO et al., 2009).

A terapia de grupo de família ficou conhecida como terapia de grupo multifamiliar, pois unia a terapia de família e a terapia de grupo, e pela união dos grupos naturais e dos desconhecidos. Ao somar as características desses grupos estabelece-se como sendo a proposta do grupo multifamiliar. Nessa prática existe uma vertente adotada para trabalhar com pacientes psicóticos e sua família que é o enfoque psicoeducacional, onde o objetivo é orientar os familiares quanto à medicação, a lidar com a doença, sobre o prognóstico e tratamento (PONCIANO et al., 2009). Porém não é suficiente, pois o trabalho com familiares vai além dessas orientações, por isso a importância de encontrar outros suportes para esses cuidadores.

Servem de exemplo os modelos que trabalham como dispositivos dando suporte as famílias e entes adoecidos, pois segundo o Ministério da Saúde (BRASIL, 2004), O CAPS proporciona várias maneiras de trabalhos terapêuticos, entre elas está o atendimento familiar e a psicoterapia grupal, pois para Lancetti (1993), essa modalidade tem sido o principal artifício terapêutico na conjuntura da nova configuração dos serviços da saúde mental, nascida após a implantação da Reforma psiquiátrica que tinha por objetivo reinserir os pacientes na sociedade. Sendo assim é nesse contexto que segundo Guanaes e Japur (2001) o ambiente grupal é considerado o local onde os membros conseguem reproduzir seus papéis relacionais vividos no dia a dia, explorando sua subjetividade.

\section{Metodologia}

Este trabalho aborda um relato de experiência acerca do trabalho com cuidadores de internos de um hospital psiquiátrico, utilizando um referencial de pesquisa qualitativa, sendo desenvolvido a partir do método heurístico, no qual o sujeito pesquisador narrará a sua experiência de forma que possibilitará compreender melhor os fenômenos envolvidos na pesquisa a partir da sua percepção. A palavra "heurística" decorre do verbo grego heurísko, que significa encontrar, descobrir. Trata-se de um método experimental que o pesquisador terá total liberdade em relatar a sua experiência a fim de descobrir a essência e o sentido desta, sem que a princípio sejam impostas regras para que não impeçam o caminho natural da autodescoberta, favorecendo o desenvolvimento de métodos e procedimentos para pesquisas futuras. O Método Heurístico potencializa a autocompreensão do fenômeno e não se preocupa em algo que tenha um fim específico ou que já tenha sido validado (HOLANDA, 2006).

Para o mesmo autor citado acima o processo heurístico compreende seis fases que se desenvolve de uma maneira natural, e que inicia a partir de uma questão ou problema que será 
respondida pelo pesquisador, deixando claro o que este procura. São elas: a) engajamento inicial, b) imersão na questão, c) incubação, d) iluminação e) explicação e por fim a f) síntese criativa.

Entende-se por engajamento inicial o momento que surge o interesse pelo tema em questão a partir do contato com algo da sua experiência identificando o foco da pesquisa. Na imersão existe uma junção de interesses que fará com que o pesquisador se empenhe fortemente no aprofundamento do tema escolhido. Na fase de incubação, todos os dados obtidos chegarão ao esgotamento. Dessa forma o pesquisador afastar-se-á do que foi obtido para que possa perceber outros dados que não estavam visíveis. As fases de iluminação e explicação apesar de ocorrerem simultaneamente, são fases distintas. A fase de iluminação é um processo espontâneo em que o pesquisador entrará em contato com questões que vão além da experiência pesquisada. E a partir daí, na fase da explicação, essas questões serão entendidas e mencionadas a partir de um diálogo com ele próprio, com as outras pessoas e com a literatura adequada. E por fim é na síntese criativa que ocorre uma representação de tudo que foi pesquisado, e a obtenção de uma produção criativa sobre o tema (SALES, 2010).

O estudo deste artigo revela os sentimentos e a percepção da autora que facilitou o grupo de família de internos de um hospital psiquiátrico que são impelidos como cuidadores dessas pessoas. Os encontros ocorreram semanalmente no hospital psiquiátrico na cidade de Crato, com duração de seis meses.

Essa experiência tem como suporte teórico o movimento da reforma psiquiátrica e família e o trabalho em grupos que serviram para melhor compreensão do estudo em questão. O método utilizado foi o da pesquisa heurística, uma vez que, para Sales (2010), o pesquisador que se utiliza deste método se envolve de forma íntima revelando sentimentos, pensamentos e sensações, a partir das análises dos dados. Sendo assim, é importante a escolha de temas principais que melhor fundamentem a experiência vivida a partir de um investigação detalhada das discussões teóricas e do relato de experiência que aqui foram contemplados.

\section{Relato da Experiência}

Descrevo aqui o meu relato de experiência enquanto estagiária de um hospital psiquiátrico na cidade de Crato - CE. Estagiei por um ano e meio nesse espaço e no último semestre fui convidada a facilitar o grupo de família. No início fiquei um pouco resistente em aceitar o convite, pois não queria deixar de lado o pavilhão feminino, onde havia passado um ano, porém acabei aceitando, pois iria conseguir conciliar estas atividades com as do grupo de família. A duração da minha participação como facilitadora foi de seis meses, com a frequência de um encontro semanal, com duração de uma hora. Era um grupo aberto e heterogêneo, pois não havia um limite para a quantidade de pessoas e também não se delimitava a idade, nem o sexo, ou outra característica neste sentido. O que eles tinham 
em comum era o fato de serem familiares de internos do hospital. Sendo assim, o número de participantes variava em torno de cinco a vinte pessoas por encontro e era composto por homens e mulheres, sendo estas a maioria a frequentar o grupo, porém a participação masculina não era de menor relevância.

Achava importante sempre planejar atividades antes do encontro, principalmente quando queríamos abordar temas determinados. As rodas de conversa também eram bastante produtivas e algumas vezes delimitava um tema para ser discutido, por outras vezes deixava correr livremente para que eles mesmos iniciassem o encontro.

Minha primeira experiência com o grupo foi no dia cinco de julho de 2013. Nesse primeiro momento, observei o quanto essas pessoas precisavam verbalizar. Sentiam-se desoladas, incompreendidas, sem informações e sem acolhimento. Nesse momento, percebi o quanto eu poderia contribuir no decorrer de outros encontros, mantendo-me como facilitadora nesse processo de construção, fortalecimento e crescimento.

A criação desse espaço de encontro e de construção foi de profunda importância, na medida em que essa intervenção abriu um leque de possibilidades para esses familiares de internos. Foi notório o fortalecimento, o aprendizado para lidar com as dificuldades, o crescimento com o compartilhamento das histórias e dos sentimentos em comum. O grupo por si só caminhava e se organizava, em seu ritmo, e eu, enquanto estagiária, oferecia o suporte a essa relação, acolhendo todas as demandas surgidas.

Alguns discursos, por relatarem tão grande sofrimento, eram preocupantes. O impulso que me vinha era o de amparar essas pessoas. Isso se tornou possível graças ao espaço de confiança que criamos, propício ao acolhimento e à compreensão, no qual seus membros expunham suas dúvidas, angústias, medos, raivas e todos os sentimentos privados pela sociedade. O grupo de família tornou-se gradativamente um ambiente acolhedor, onde todos estavam atentos às falas uns dos outros e sentiamse seguros para compartilhar tudo, experiência oposta a vivenciada fora dele, na qual se deparavam com a hostilidade e a intransigência da comunidade.

Em todos os momentos com o grupo, me sentia pertencente a ele, me envolvia em cada história, e me sentia livre para me expressar sempre que necessário. Cada relato tinha sua especificidade, e me capturavam de formas diferentes. Algumas pessoas demonstravam medo por não saberem lidar com as crises, outras sentiam vergonha pelos estigmas trazidos pela doença e por não serem bem vistas diante da sociedade, outras ainda vinham cheias de dúvidas pela falta de informações acerca de como agir diante da patologia. A cada encontro sentia-me inteiramente envolvida com o grupo, e percebia a importância dessa entrega, que favorecia o fortalecimento e o vínculo entre todos.

Muitos cuidadores não conseguiam segurar o choro durante as reuniões, relatando o impedimento de chorar nos momentos do dia a dia, e usavam o espaço do grupo de família para aliviar todas as tensões adquiridas nessa luta diária. Nesses momentos me sentia muito comovida e sempre 
me aproximava para dar um abraço com a intenção de que se sentissem seguras e acolhidas. Lembrome de um senhor de 49 anos que tinha um irmão internado há um mês, e ele não faltava a nenhum encontro, participando de forma efetiva de todas as atividades propostas. Ele relatava "eu me preocupo muito com meu irmão, às vezes ele não lembra de mim, e diz que não gosta de mim, mas eu vou cuidar dele até o fim". Ao ouvir esse relato, percebia tanta bondade nesse senhor, tanta dedicação e ao mesmo tempo quando ele falava "não tenho filhos, não casei, pois não temos mais mãe, nem pai, somos só nós dois", percebia muita solidão pois ele havia abdicado de muitas coisas para cuidar do seu irmão.

Pude observar o quão vulneráveis ficavam os cuidadores dos internos, e a quantidade de dúvidas trazidas acerca do problema dos seus familiares, do diagnóstico e prognóstico da doença. Muitas vezes sentiam-se desamparados sem ninguém pra ouvi-los e ampará-los. Percebi a importância do acolhimento para essas pessoas e sentia que em cada um que dele participava surtia grandes efeitos. Em todos os encontros mantive-me sempre receptiva e aberta a cada relato, sem julgamento ou críticas e dessa forma as pessoas conseguiam falar livremente. Uma das participantes do grupo relatou: "antes desse grupo, ficava em casa estressada e tomando remédio, agora não, aqui posso me abrir e isso me acalma".

Lá, as pessoas podiam compartilhar suas experiências e havia uma identificação com o relato do outro, com isso pude compreender o poder de uma grupoterapia, pois o vínculo ficava totalmente estabelecido a partir das suas histórias. Notei também que mesmo as pessoas que não participavam eram tocadas pelo discurso do grupo e saíam do encontro aliviadas e esclarecidas.

Percebia o quanto alguns dos membros estavam esgotados, e pensava: "que bom que o grupo de família existe", nele essas pessoas se entregavam e expunham todos os sentimentos guardados. Muitas vezes não tinham tempo nem de olhar para si mesmo, nem de saber mais do que gostavam, não conseguiam ter um minuto do dia para seus próprios afazeres. Tudo girava em torno do cuidado, do zelo por esses parentes que estavam em situação tão vulnerável e delicada. E era no grupo que eles tinham a chance de falar livremente, de se sentirem vivos, de se sentirem acolhidos sem julgamento, sem receio de que pudessem ser criticados.

Nos vários relatos, observei o medo do desamparo, proveniente do receio do fechamento do hospital e da não existência de outro suporte para seus familiares adoecidos. Disse-me uma mãe: "Resolvi um dia levar minha filha pro CAPS, quando chegamos lá, o médico encaminhou imediatamente para o hospital psiquiátrico, pois disse que ela estava atrapalhando as outras pessoas que estavam mais orientadas". Ouvi muitos relatos coerentes com a realidade da região e sentia-me de mãos atadas neste sentido, por saber que não existia lugar adequado para atender essas demandas. Um fato agravante era o de muitos pacientes serem de cidades pequenas que não possuíam dispositivos de saúde para acolhê-los. Como dizia um membro do grupo: "na minha cidade não tem CAPS, não tem nada que ajude meu filho, só a polícia mesmo, então é o jeito trazer pra cá”. 
As condições do hospital eram péssimas em virtude do movimento reformista e da necessidade da substituição do hospital psiquiátrico por outros dispositivos, e a família por mais que soubesse disso, não abria mão da internação dos seus, pois viam nela uma saída para a minimização das crises ou o alívio ao trabalho constante que é exigido dos cuidadores. Funcionava ainda como um espaço onde eles poderiam tirar das suas costas um peso incompreendido pela sociedade, uma forma de conforto para suavizar tanto sofrimento. Uma participante falava: "eu fico preocupada com o que acontece lá dentro, pois uma paciente quase arranca a língua da minha irmã, sangrou muito, mas é o jeito trazer e interná-la aqui". Percebia a preocupação dos familiares, principalmente nos momentos de crise dos seus parentes, porque apesar de conviverem há muito tempo com essa situação, não tinham tanta informação sobre a doença, e muitas vezes não sabiam lidar com esses momentos delicados. Pensavam que a única saída seria a internação.

Outra queixa dos familiares dizia respeito às condições financeiras e isso atrapalhava na relação paciente e família por não poderem fazer visitas constantes aos seus entes queridos, na maior parte das vezes o paciente não compreendia e nem aceitava essas circunstâncias. Os familiares desejavam acompanhar mais de perto, e eram impedidos por esses fatores econômicos. Observa-se isso nos dois relatos que seguem: "se eu pudesse eu vinha todo dia visitar meu marido, mas eu moro em outra cidade e não tenho dinheiro pra ficar vindo", "meu filho chora quando eu vou embora, eu só venho às quintas-feiras, porque a passagem é cara e eu aproveito o dia do grupo de família”. A situação financeira realmente era um fator de vulnerabilidade tornando-se mais uma dificuldade nessa relação de cuidador e interno.

O grupo sempre colocava como dificuldade a relação pessoal com seu familiar internado, pois muitas vezes este se tornava agressivo e hostil com seu cuidador, e dessa forma o familiar se sentia incompreendido e entristecido por se dedicar tanto e em troca receber insultos e destratos. Por outro lado, não pensavam em desistir dessa batalha, mesmo com todas essas dificuldades, no fundo esses cuidadores só queriam o bem estar do seu ente querido e conseguir viver de uma forma harmoniosa e integrada vencendo todos os preconceitos, estigmas e desafios. Uma mãe falava em um tom baixo "já apanhei do meu filho e ele já me ameaçou com uma faca, mas eu não posso abandoná-lo de jeito nenhum". Dava pra perceber a partir da voz e do olhar dessa mãe, o tamanho da dor que perpassava em sua fala, e no grupo de família ela conseguia expor esses sentimentos sendo acolhida e apoiada por todos.

No final de cada encontro os participantes sempre agradeciam e relatavam a importância da existência desses momentos. Deixavam claro a importância do grupo para o enfrentamento da luta diária e em meio a tantos sentimentos misturados. Além das preocupações com seu familiar, também existiam seus conflitos pessoais, constantemente muitas vezes expostos no grupo de família e acolhidos por todos os membros. Compartilhavam ainda os sonhos e desejos, e a esperança de conquistá-los e de viverem dias melhores. Uma das participantes falava que queria muito abrir uma 
loja pra ela: "Quero ter meu próprio negócio, sonho com isso, ter uma loja de roupas, eu costuro e sei fazer muita coisa bonita". As pessoas saíam do encontro mais otimistas e com mais disposição de dedicar-se com afinco na realização de seus objetivos, isso me trazia a sensação de dever cumprido.

No último encontro os participantes relataram a importância do grupo de família e o quanto este foi acolhedor e benéfico para eles. Esse feedback foi fundamental para que eu pudesse perceber a evolução do grupo durante esse período de seis meses e a satisfatoriedade dos resultados para todos.

Essa experiência foi finalizada no mês de Janeiro de 2014 por problemas relacionados à própria instituição. Apesar de grande contribuição e dedicação por parte dos estagiários, muitos empecilhos foram colocados para que pudéssemos dar continuidade ao estágio. Minha vontade de continuar facilitando o grupo de família permanece latente, mas a experiência que tive durante esse período foi extremamente válida, em especial, para o meu crescimento profissional, uma vez que esse aprendizado serviu de base para que eu me torne a profissional humana, dedicada e preparada que eu almejo ser.

\section{Resultados e Discussões}

A dinâmica que envolve um grupo de família é muito produtiva e possibilita grande crescimento, autonomia, acolhimento e mudança. Na minha experiência no grupo, esses aspectos foram percebidos claramente, pois os familiares saíam a cada encontro com um novo olhar para as situações cotidianas que lhes causavam angústias. Como já diziam Yalom e Molyn (2006), essa relação entre os membros do grupo incluindo o terapeuta com suas técnicas e intervenções, favorece o crescimento e a mudança, além disso através do compartilhamento das experiências, os membros aprendem a lidar com os problemas de uma forma mais consciente.

Segundo Ponciano et al. (2009), o enfoque psicoeducacional é usado para trabalhar com os pacientes e com a família de pessoas com transtornos mentais, que orienta os familiares no manejo com a doença e com a medicação, explicando o prognóstico e tratamento. Eu percebi que é muito importante trabalhar esses aspectos educativos, pois o grupo apresentava muitas dúvidas em relações a essas questões. Por outro lado, as demandas do grupo iam além disso, uma vez que eles já chegavam ao encontro verbalizando várias situações e fatos subjetivos que lhes causavam angústias. Dessa forma senti que o acolhimento e a relação estabelecida entre o grupo favoreciam ainda mais no crescimento e na autonomia dos participantes.

O grupo foi iniciado com uma quantidade pequena de componentes, em torno de cinco pessoas, porém a cada encontro esse número aumentava, totalizando ao seu término em vinte pessoas. Vale salientar que havia certa rotatividade em relação aos seus integrantes, pelo fato da necessidade de internação do familiar e da adequação ao horário de visitas. Pelas características descritas 
anteriormente, classifica-se esse grupo como aberto, visto que, segundo Guimarães et al. (2008), o grupo que está disposto a receber sempre novos participantes se trata de um grupo aberto. Eram pessoas com características diferentes, pois participavam do grupo: adolescentes, mães, pais, irmãos, avós, tios, enfim, o grupo era heterogêneo visto que para Guimarães et al. (2008), os grupos heterogêneos são aqueles que recebem variações nas características sejam físicas, de idade, de classe social, entre outras. Esses autores discorrem que os grupos se dividem em abertos e fechado, homogêneos e heterogêneos.

Um fator bem importante para o grupo ter funcionado, foi a boa interação entre os integrantes, já que o grupo podia se expressar sem medo de ser julgado, uma vez que todos estavam ali num mesmo contexto e propósitos semelhantes. Contel e Guimarães (2009), falam da importância dessa interação e que a força terapêutica parte dessa boa relação entre os membros.

Ao longo dessa experiência percebi o poder de um grupo terapêutico, o quanto favoreceu as pessoas que dele participaram. Observei no olhar, no comportamento, nas falas dessas pessoas o quanto foi significativo participar desse grupo. Eu senti o quanto eles ficavam fortalecidos e aliviados ao compartilharem experiências semelhantes, ao perceberem que não estavam sozinhos nessa luta constante contra suas dores, dúvidas e desafios. Yalom e Molyn (2006) consideram um setting de um grupo terapêutico como uma ferramenta muito poderosa, que pode ser utilizada no contexto da saúde mental, incluindo a família e oferecendo-lhe suporte e acolhimento.

Foi uma experiência muito importante e além do aprendizado que esse trabalho me proporcionou, percebi o quanto essa prática é eficiente. A cada encontro sentia que o meu papel estava sendo contemplado, pois aos términos dos encontros experimentava uma sensação de dever cumprido, e isso era visível a partir dos relatos daquelas pessoas e de seus semblantes. Constatei o quanto é relevante usar da psicoterapia de grupo para trabalhar com pessoas em situações vulneráveis, o que a torna uma ferramenta indispensável como dispositivo de produção de cuidado.

\section{Considerações Finais}

Fica claro nessa experiência com o grupo de família como é importante acolher os familiares que cuidam de pessoas com transtorno mental. Os benefícios que cada participante colhe nesse espaço de grupo são variados, e isso faz com que essas pessoas possam continuar sua vida de uma forma mais digna, feliz e cheia de esperança, tendo a certeza que não estão sozinhos nessa luta e que tem espaços que possam compartilhar sem serem julgados e discriminados, podendo verbalizar as angústias e sofrimentos que perpassam por suas vidas dia após dia.

Os trabalhos realizados com grupos de família pelo CAPS e ESF mostram os resultados significativos para as famílias, e consequentemente trazem benefícios para os pacientes, assim como 
esse trabalho realizado no hospital psiquiátrico em estudo, mostra como a relação entre os cuidadores e internos torna-se mais fácil, incluindo a aceitação do problema, bem como a melhoria nessa relação familiar, a partir do que é verbalizado pelos participantes.

Ouvir as questões subjetivas de cada participante abre um leque de possibilidades e crescimento para a vida dessas pessoas e isso só aumenta a certeza do poder que tem um grupo terapêutico direcionado a cuidadores de pessoas com transtorno mental, pois nesse espaço acolhedor poderão compartilhar seus medos, dúvidas, vitórias, sonhos, desejos, enfim, todos os sentimentos e vivências que perpassam por cada um.

Após essa experiência com grupos, acredito no poder dos grupos terapêuticos, e nas possibilidades que se abrem para que esses cuidadores e familiares consigam nesses espaços de acolhimento e compartilhamento de experiências, ressignificar conteúdos que fazem parte das suas histórias de vida. Faz-se necessária o uso dessa ferramenta em todos os dispositivos de saúde não podendo ficar instituição alguma sem esse tipo de intervenção. Com isso ressalto que esse trabalho com o grupo de família poderá ainda render muitos frutos contribuindo para construir outras pesquisas para que cada vez mais possa se pensar na melhoria da vida de pessoas que estão em alguma situação de vulnerabilidade e que possam se beneficiar por meio destes estudos.

\section{Referências}

AMARANTE, P. Loucos pela vida: a trajetória da reforma psiquiátrica no Brasil. $5^{\mathrm{a}}$ reimpressão - $2^{\mathrm{a}}$ edição, revista e ampliada: Rio de Janeiro: Fiocruz, 2010.

BRASIL. Temas de saúde mental. MINISTÉRIO DA SAÚDE. Brasília, 1998.

CAMPOS, P. H. F.; SOARES, C. B. Representação da sobrecarga familiar e adesão aos serviços alternativos em saúde mental. Psicologia em Revista, Belo Horizonte, v. 11, n. 18, p. 219-237, dez. 2005.

CONTEL, José Onildo B.; VILLAS-BOAS, Maria Aparecida. Psicoterapia de grupo de apoio multifamiliar (PGA) em hospital-dia (HD) psiquiátrico. Rev. Bras. Psiquiatr. vol.21 n.4 São Paulo Dec. 1999.

FREUD, Sigmund. "Psicologia de Grupo e Análise do Eu" (1921). In. Obras psicológicas completas, edição Standard, vol.XVIII. Rio de Janeiro: Imago, 1996.

GONÇALVES AM, SENA RR. A reforma psiquiátrica no Brasil. Rev Latino-americana Enfermagem 2001 março;

GRANDI, A. L. DE; WAIDMAN, M. A. P. Convivência e Rotina da Família Atendida em CAPS. Ciênc Cuid Saude 2011; 10(4):763-772. 
GUANAES, C.; JAPUR, M. Grupo de Apoio com Pacientes Psiquiátricos Ambulatoriais em Contexto Institucional: Análise do Manejo Terapêutico Psicol. Reflex. Crit. vol.14 no.1 Porto Alegre. 2001.

GUimarães, A. C. P. C., \& CONTEL, J. O. B. (2009). Psicoterapia de grupo em hospitaldia psiquiátrico. Paidéia (Ribeirão Preto) vol.19 no.44 Ribeirão Preto Sept./Dec. 2009.

GUIMARÃES, A. C. P.C. et al. GRUPOTERAPIA COMO MODALIDADE DE TRATAMENTO EM AMBULATÓRIO DE SAÚDE MENTAL. In: SIMPÓSIO INTERNACIONAL DE EDUCAÇÃ̃ (2. : 2008 : Bauru, SP). Anais... Bauru, SP: USC, 2008.

HOLANDA, A. Questões sobre pesquisa qualitativa e pesquisa fenomenológica. Revista Análise Psicológica 3(XXIV): 363-372, 2006.

LANCETTI, A. Clínica grupal com psicóticos: A grupalidade que os especialistas não entendem. In LANCETTI, A. (Org), Saúde e loucura: Grupos e coletivos, (nº 4, pp.155-171). São Paulo: Hucitec, 1993.

MACEDO, F. M. S.; ANDRADE, M.; SILVA, J. L. L. A reforma psiquiátrica e implicações para a família: o papel do enfermeiro no programa saúde da família. Informe-se em promoção da saúde. v.5, n.2. p.19-23, 2009.

MELLO R. A construção do cuidado à família e a consolidação da reforma psiquiátrica R Enferm UERJ 2005; 13:390-5.

MELMAN, J. Família e Doença Mental: repensando a relação entre profissionais de saúde e familiares. São Paulo: Escrituras Editora, 2a ed. 2006.

OSORIO, LUIZ CARLOS. II Valle, Maria Elisabeth Pascual do. Terapia familiar - Manual I. Pascual do Valle (org.). - Dados eletrônicos: - Porto Alegre: Artmed, 2009. Editado também como livro impresso em 2009. ISBN 978-85-363-1827-1.

PONCIANO, E. L. T., Cavalcanti, M. T., Féres-Carneiro, T. Observando os grupos multifamiliares em uma instituição psiquiátrica. Instituto de Psiquiatria da Universidade Federal do Rio de Janeiro; 2009.

SALES, Y. N. Incursões metodológicas em pesquisa de tendência formativa na experiência de psicoterapeutas centrados na pessoa: na vanguarda do que Carl Rogers concebeu. Dissertação de Mestrado, Programa de Pós-Graduação em Psicologia, Universidade de Fortaleza, Fortaleza, Ceará, 2010.

SANTIN, G.; KLAFKE, T. E. A família e o cuidado em saúde mental. Barbarói, Santa Cruz do Sul, n. 34, jan/jul. 2011.

YALOM, I.D.; MOLYN, M.L. Psicoterapia de grupo: teoria e prática; tradução Ronaldo Cataldo Costa. Porto Alegre: Artemed, 2006.

ZIMERMAM D. E. Manual de técnica psicanalítica: uma revisão. 1 ed. Porto Alegre: Artmed, 2004. p. 472. 
ID on line REVISTA DE PSICOLOGIA

http://idonline.emnuvens.com.br/id

ISSN on-line: 1981-1179

isen line

\section{Como citar este artigo (Formato ABNT):}

BARRETO, A.K.M.; PINHEIRO, L.M. Grupo de família: Relato de Experiência acerca do trabalho com cuidadores de um Hospital Psiquiátrico na Cidade de Crato-CE. Id on Line Revista de Psicologia, Julho de 2015, vol.9, n.27. p. 178-193. ISSN 1981-1189.

Recebido: 11/02/2015

Aceito:19/02/2015 